\title{
LEITO DE DRENAGEM: SISTEMA NATURAL PARA REDUÇÃO DE VOLUME DE LODO DE ESTAÇÃO DE TRATAMENTO DE ÁGUA
}

\section{DRAINING BEDS: NATURAL SYSTEM FOR SLUDGE VOLUME REDUCTION IN THE WATER TREATMENT PLANT}

\section{CALI LAGUNA ACHON}

Engenheira Civil pela Universidade Federal de São Carlos (UFSCar). Doutoranda em Engenharia Hidráulica e Saneamento pela EESC/USP

\section{MarCELo Melo BarRoso}

Engenheiro Civil - Mestre em Hidráulica e Saneamento pela Universidade de São Paulo (EESC/USP). Doutor em Engenharia Hidráulica e Saneamento pela EESC/USP. Professor da Universidade Federal de Rondônia

\section{JoÁo Sérgio CoRdeIRo}

Engenheiro Civil - Mestre e Doutor em Hidráulica e Saneamento pela Universidade de São Paulo (EESC/USP). Professor do Departamento de Engenharia Civil da UFSCar. Professor do Programa de Pós-Graduação de Hidráulica e Saneamento da EESC/USP. Presidente da Associação Brasileira de Ensino de Engenharia - ABENGE

Recebido: 06/07/07 Aceito: 15/01/08

\section{RESUMO}

As Estações de Tratamento de Água (ETAs) tem funcionamento semelhante a uma indústria e podem em diversas etapas gerar resíduos que, na maioria das ETAs, são lançados nos corpos d'água sem tratamento. Neste trabalho avaliou-se o desempenho de Leitos de Drenagem, para o desaguamento de lodo, provenientes de ETAs de ciclo completo que empregam sulfato de alumínio e cloreto de polialumínio (PACl), como coagulantes. Analisou-se as características, a drenagem e secagem dos amostras de lodo e característica do drenado. Os Leitos de Drenagem mostraram-se eficientes para desaguamento e redução de volume de lodo de ETA, de forma natural, sem consumo de energia ou adição de produtos químicos. Obteve-se, aos sete dias, reduçôes da ordem de $87 \%$ em volume para os lodos de $\mathrm{PACl}$ e $83 \%$ para o lodo de Sulfato de Alumínio e teor de sólidos totais $28 \%$ e $31 \%$ respectivamente.

PALAVRAS-CHAVE: Tratamento de água, lodo, coagulante, sistemas naturais, leitos de secagem, leito de drenagem.

\begin{abstract}
In this work the performance of Draining Beds for sludge dewatering was assessed. The sludge was provided from full cycle Water Treatment Plants (WTPS) that employ aluminum sulfate and polyaluminium chloride (PACl) as coagulants. The characteristics, drainage and drying of samples of sludge and characteristic of drained were analysed. The Draining Beds were shown to be efficient for dewatering and sludge volume reduction in the WTP, in a natural way, without energy consumption or adding of chemical products. On the seventh day, it was possible to obtain reduction around $87 \%$ in volume for PACl sludge and $83 \%$ for the aluminum sulfate sludge and total solids content of 28 and $31 \%$ respectively.
\end{abstract}

INTRODUÇÃO

As Estações de Tratamento de Água (ETA) tem funcionamento semelhante a uma indústria onde uma determinada matéria prima (água bruta) é trabalhada, através de diversas operaçóes e processos, resultando em um produto final (água tratada). Esses sistemas podem em diversas etapas gerar resíduos com as mais diferenciadas características. Assim, um dos problemas a ser equacionado nas ETAs diz respeito aos resíduos gerados e como definir seu destino final.
Os resíduos gerados nas ETAs são, principalmente, a água de lavagem de filtro e o lodo.

$\mathrm{Na}$ maioria das ETAs esses resíduos são lançados nos corpos d'água sem tratamento. Os lodos de ETAs são classificados pela série de normas NBR-10.004 (2004) como resíduos sólidos, não sendo permitido seu lançamento in natura em águas superficiais. A Política Nacional de Recursos Hídricos, Lei 9.433/97 estabelece que, o lançamento de resíduos líquidos, sólidos ou gasosos, tratados ou não,
KEYWORDS: Water treatment, sludge, coagulant, natural systems, drying beds, draining bed. com o fim de sua diluição, transporte ou disposição final em corpos d'água, além de outros usos que alterem o regime, a quantidade ou a qualidade da água, está sujeita à outorga do Poder Público (Brasil Leis, 1997).

O lançamento dos resíduos gerados em ETAs, em corpos d'água, pode ser considerado crime ambiental, de acordo com a Lei 9.605/98, devido aos efeitos diretos causados ao ambiente aquático do corpo receptor e danos à fauna aquática.

A atenção à questão da geração, lançamento e disposição de resíduos de 
ETAs teve início nos Estados Unidos, a partir de 1930. Todavia, ainda não se dispunham de técnicas ou procedimentos que permitissem soluções definitivas ou restriçōes bem definidas (Cordeiro, 1993).

As tecnologias para redução do volume de lodo produzido nas ETAs, mediante remoção da água livre e nos interstícios dos sólidos, podem ser classificadas como: Sistemas Mecânicos (centrífugas, filtros-prensa, prensa desaguadora, filtros a vácuo) e Sistemas Naturais (lagoas de lodo e os leitos de secagem).

Os sistemas mecânicos muitas vezes necessitam de alto custo para implantação, operação e manutenção. Já a remoção de água em sistemas naturais não necessita de grandes investimentos para implantação, tampouco para operação e manutenção, porém necessita de grandes áreas.

Nos Estados Unidos, segundo Murray e Dillon (1994), os leitos de secagem são utilizados em 10\% das 469 ETAs estudadas e as lagoas de lodo em $67,8 \%$. Vale ressaltar que devem ser tomados sérios cuidados, pois, nos EUA, devido às baixas temperaturas ocorre $o$ congelamento do lodo, o que contribui para a redução de volume. Muitos países se baseiam em modelos internacionais sem analisar criteriosamente todas as especificidades inerentes ao sistema. Por outro lado, em países tropicais como o Brasil, as condições climáticas podem favorecer e potencializar o uso de sistemas naturais.

\section{SISTEMAS NATURAIS DE REDUCÃO DE VOLUME DE LOBOO DE ETA}

Os lodos são constituídos de fase sólida e fase líquida. Ressalta-se que a maior parcela destes resíduos corresponde à fase líquida, subdividida em diferentes fraçōes: água livre, água intersticial, água vicinal e água de hidratação (Smollen e Kafaar, 1994) e (Vesilind e Hsu, 1997). As quantidades relativas das diferentes frações de água determinam as características de retenção de água dos resíduos e, conseqüente, desempenho dos sistemas de remoção de água (Reali, 1999).

A estrutura dos sólidos presentes nos lodos de ETAs é muito complexa, composto por partículas muito pequenas fornecendo um arranjo que pode dificultar a remoção de água. Além disso, a sedimentação das partículas, que passam a ocupar os vazios da massa sólida, dificulta a passagem da água livre.

Uma solução para o lodo seria sua disposição em aterros. No entanto, o volume é elevado e os custos de disposição e transporte também. Assim, a redução de seu volume, através da drenagem da água livre e secagem, torna-se desejável.

Nesse sentido, um dos problemas mais sérios é a redução do volume de lodo gerado nas ETAs. Esta redução pode ser realizada com a remoção da água livre e nos interstícios dos sólidos através de sistemas naturais ou mecânicos. A definição do tipo de sistema a ser utilizado depende de inúmeros fatores como área necessária para implantação, custo da área, condiçôes climáticas, custo dos equipamentos, operação, preparo de recursos humanos para operação, necessidade de condicionamento, entre outros.

A remoção natural de água livre dos resíduos de ETAs pode ser realizada por Sistemas Naturais de redução de volume, que são as Lagoas de lodo e os Leitos de secagem. Vale salientar que, no Brasil, o uso de sistemas naturais de tratamento de resíduos de ETAs possui grande potencial de aplicação, principalmente devido a disponibilidade de área, condições climáticas favoráveis e por ser um sistema de baixo custo, que não necessita de produtos químicos e energia elétrica.

\section{Lagoa de lodo}

A remoção de água em lagoas de lodo é um método que pode ser utilizado quando há disponibilidade de área a baixo custo. Esta remoção pode ocorrer em três fases: retirada da água sobrenadante, evaporação e transpiração.

O projeto de lagoas de lodo inclui: sistema de tubulações para entrada de lodo e saída do decantado, sistema de bombeamento (se necessário) e equipamentos para remoção mecânica de lodo.

O sobrenadante pode ser removido continuamente ou de forma intermitente, podendo retornar ao sistema de tratamento. Quando a remoção da água sobrenadante, através de dispositivos, não é mais possível, inicia-se a evaporação. Ressalta-se que a evaporação é o principal fator para o desaguamento.

O tempo para desaguamento pode variar bastante, inclusive meses, em função principalmente das condições climáticas e operacionais.

Hubbs e Pavoni (1974) e Cornwell (1987) citam que nas lagoas a camada superior de lodo apresenta boa secagem, o que não ocorre nas camadas inferiores.

\section{Leito de secagem}

A tecnologia de leitos de secagem tem sido utilizada para remoção de água de resíduos de diversos tipos de tratamento de águas residuárias, e em alguns casos, de abastecimento desde o início do século XX (1900) e a partir de então, vem sendo aplicada praticamente sem mudanças consideráveis em sua estrutura física.

Dentre as evoluções ocorridas nesse sistema, podem ser citadas: leito de secagem a vácuo, leitos de secagem de tela em cunha, tradicionais e leitos pavimentados.

Nos sistemas tradicionais a estrutura básica é formada de: camada suporte; meio filtrante e sistema drenante.

Cordeiro (1993) e (2001), estudou a possibilidade de modificação da estrutura tradicional de leito de secagem e observou que a colocação de manta de geotêxtil sobre a camada filtrante do leito, possibilitava a remoção mais efetiva da água livre dos lodos. Os resultados obtidos evidenciaram que a areia e a espessura da camada filtrante não eram decisivas na remoção de água livre.

Os estudos evoluíram e no PROSAB 2 - Tema 4 (Cordeiro, 2001) foi desenvolvida a proposta de um leito modificado 2 , onde a areia foi removida e o leito constituído de uma camada de brita $01 \mathrm{com} 5 \mathrm{~cm}$ e sobre ela manta geotêxtil. O tempo de drenagem da água livre diminuiu bruscamente com o novo arranjo (modificado 2), recebendo a denominação de Leito de Drenagem.

No Leito de Drenagem, o tempo de remoção de água constituiu-se na somatória do tempo de drenagem e de evaporação da água, assim, tanto as condiçôes de drenagem quanto às condiçôes climáticas têm devido importância. Após a drenagem da água livre, a secagem da massa de lodo ocorre por meio da evaporação, e as variáveis climáticas, tais como, umidade relativa do ar, ventilação podem ser de suma importância para o melhor desempenho de desaguamento.

Achon e Cordeiro (2004) analisaram os sistemas naturais de redução 
de volume, comparando um sistema de lagoas de lodo existente em uma ETA convencional de ciclo completo, com o Leito de Drenagem desenvolvido durante o projeto de pesquisa PROSAB 2-Tema 4

Neste estudo foi observado que nas lagoas de lodo, a remoção de água presente no lodo realizava-se com dificuldade em virtude de sua concepção, levando semanas e até meses para a secagem do lodo. Já nos leitos de drenagem verificaram-se reduções de 75 a $85 \%$ do volume em sete dias. Os resultados obtidos com a caracterização do drenado apresentaram baixos valores de cor, turbidez e elevada redução da concentração de sólidos.

Assim, constataram-se o desempenho e potencial de aplicação dos Leitos de Drenagem, que se mostraram superiores as lagoas de lodo em vários aspectos.

\section{OBJETIVO}

Avaliar o desempenho de Leitos de Drenagem para o desaguamento de lodos, provenientes de Estaçóes de Tratamento de Água de ciclo completo que empregam diferentes coagulantes, sulfato de alumínio e cloreto de polialumínio.

\section{METODOLOGIA}

O trabalho foi divido em cinco etapas, apresentadas a seguir.

- Ensaios preliminares;

- Coleta e caracterização das amostras de lodo;

- Aplicação dos lodos de decantadores nos protótipos dos leitos de drenagem, com monitoramento das variáveis operacionais e de controle;

- Coleta e caracterização do drenado;

- Análise dos resultados.

Foram coletadas $50 \mathrm{~L}$ de volume de amostra de lodo nos decantadores de duas ETAs convencionais de ciclo completo, descritas na Tabela 1 .

Lodo proveniente de coagulante Sulfato de Alumínio (ETA A): estação de tratamento de água com as etapas de coagulação, floculação, decantação convencional e filtração. Apresenta adição de cal após a coagulação. O lodo é acumulado, em média, por 2 meses até a lavagem do decantador.

Lodo proveniente de coagulante Cloreto de Polialumínio (ETA B): estação de tratamento de água com as eta- pas de pré-oxidação (cloro), coagulação, adição de carvão ativado, floculação, decantação convencional e filtração. $\mathrm{O}$ lodo é acumulado, em média, por 1 mês até a lavagem do decantador.

Na Figura 1 apresenta-se o protótipo do Leito de Drenagem desenvolvido por Cordeiro (2001), que foi utilizado neste trabalho.

As dimensões e configuração do protótipo do Leito de Drenagem são apresentadas na Figura 2.

Tabela I - Estações de Tratamento de Água onde foram coletadas as amostras de lodo

\begin{tabular}{ccccc}
\hline ETA & Vazão (L/s) & Coagulante & $\begin{array}{c}\text { Tratamento de } \\
\text { lodo }\end{array}$ & Descarte de lodo \\
\hline ETA A & 500 & $\begin{array}{c}\text { Sulfato de } \\
\text { Alumínio }\end{array}$ & Não possui & Córrego \\
ETA B & 260 & $\begin{array}{c}\text { Cloreto de } \\
\text { Polialumínio }\end{array}$ & Não possui & Córrego \\
\hline
\end{tabular}

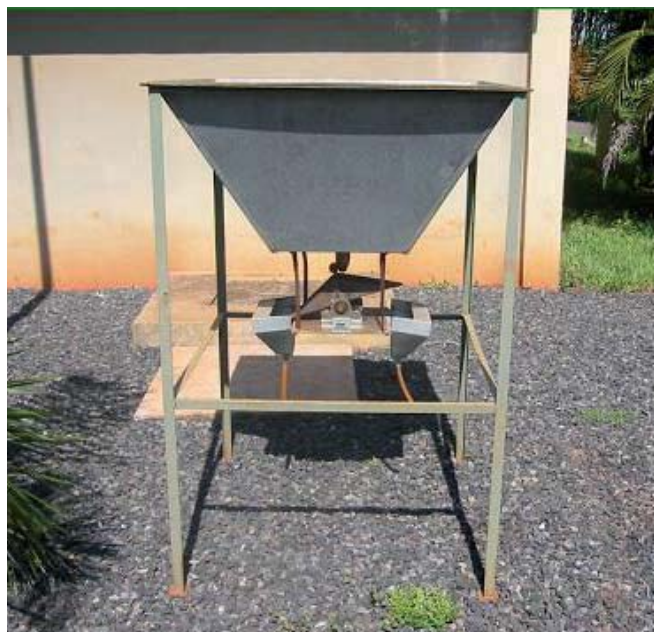

Figura I - Protótipo de leito de drenagem desenvolvido por Cordeiro (200I)

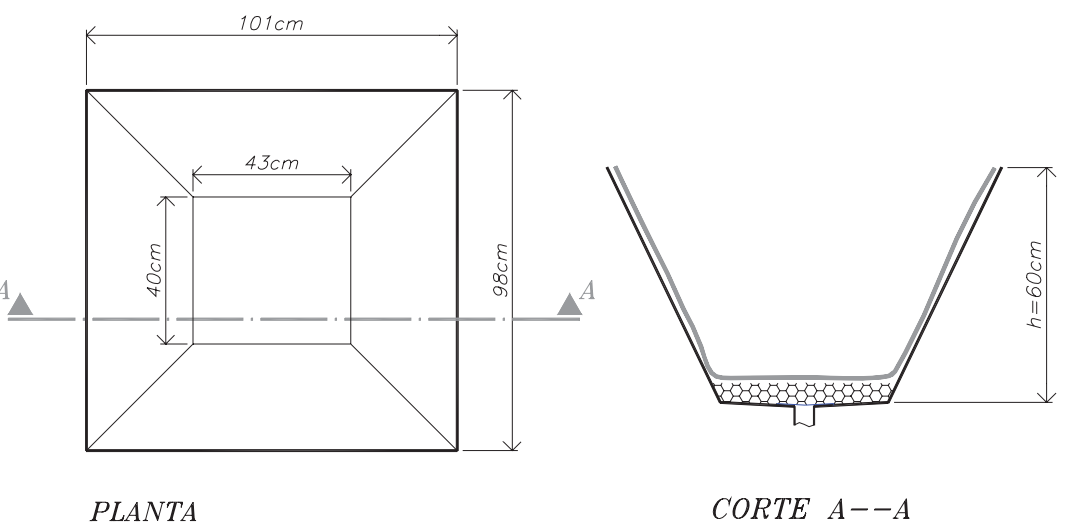

Figura 2 - Dimensões do Leito de Drenagem usado nos ensaios 
ficial de $600 \mathrm{~g} / \mathrm{m}^{2}$, que apresentou o melhor desempenho de drenagem nos experimentos realizados por Cordeiro (2001) e Fontana (2004). As características da referida manta são apresentadas na Tabela 2.

Antes da aplicação das amostras de lodo nos leitos de drenagem determinaram-se as concentraçôes de sólidos totais. As variáveis de controle do ensaio pré-definidas são: concentração de sólidos ao longo do tempo, volume de lodo aplicado, volume de água drenado e o tempo de remoção da água dos lodos.

Após a aplicação do lodo nos protótipos foram coletadas amostras dos drenados nos tempos de $5 \mathrm{~min}$, $20 \mathrm{~min}, 40 \mathrm{~min}, 60 \mathrm{~min}$ e a cada 60 minutos até encerrar a fase drenagem. Também foram coletadas amostras do lodo retido para determinação do teor de sólidos (\%), prosseguindo após o encerramento da fase de drenagem com determinações diárias.

Os resultados apresentados neste trabalho referem-se a um ensaio sistematizado realizado após a definição de um procedimento metodológico, obtida através de ensaios preliminares realizados.

As mantas foram retiradas com a massa seca de sólidos, após a secagem do lodo (7 dias). As massas secas de sólidos foram coletadas e caracterizadas, quanto à concentração final de sólidos. Ressalta-se que durante os diferentes ensaios preliminares e final não foi feito troca de mantas, somente limpeza superficial.

Fontana (2004) realizou ensaios utilizando cinco vezes a mesma manta, destacando que a manta utilizada neste tipo de ensaio não demonstra necessidade de troca, pois possui baixa colmatação. Os mecanismos de retenção e colmatação das mantas tem sido estudadas por Freitas (2003).

A avaliação do desempenho deste sistema para redução de volume de lodo das ETAs que utilizam Sulfato de Alumínio e Cloreto de Polialuminio, fez-se mediante monitoramento das variáveis apresentadas na Tabela 3 durante a operação do protótipo.

Além das variáveis operacionais foi monitorada uma variável climatológica, a precipitação.

Os métodos usados para caracterização dos resíduos e drenados $(\mathrm{pH}$, turbidez, cor, teor de sólidos totais e sólidos sedimentáveis) seguiram métodos preconizados pela APHA/AWWA/ WEF (2001).

Tabela 2 - Características da manta geotêxtil utilizada nos ensaios de desaguamento por leito de drenagem

\begin{tabular}{ccc}
\hline Características & Unidades & $600 \mathrm{~g} / \mathrm{m}^{2}$ \\
\hline Espessura & $\mathrm{mm}$ & 4,5 \\
Porosidade & $\%$ & $>90$ \\
Permeabilidade normal & $\mathrm{cm} / \mathrm{s}$ & $3 \times 10^{-1}$
\end{tabular}

Abertura

um

60

\section{RESULTADOS E DISCUSSÕES}

A seguir, apresentam-se os resultados da avaliação de desempenho dos Leitos de Drenagem para o desaguamento de lodos, provenientes de Estações de Tratamento de Água de ciclo completo que empregam diferentes coagulantes, sulfato de alumínio e cloreto de polialumínio.

\section{Caracterização das amostras de lodo}

$\mathrm{Na}$ Tabela 4, apresentam-se a porcentagem de sólidos totais e sólidos sedimentáveis das amostras de lodo de sulfato de alumínio e $\mathrm{PACl}$ utilizadas nos ensaios.

Na Figura 3 representam-se graficamente os resultados dos ensaios de coluna de sedimentação para os lodos de sulfato de alumínio e PACl. Observou-se que o lodo proveniente de $\mathrm{PACl}$ apresentou maior sedimentabilidade até 1 hora. Porém, após 24 horas o lodo proveniente de sulfato de alumínio o suplantou.

\section{Drenagem da água livre dos lodos nos leitos de drenagem}

Os resultados apresentados nas Figuras 4, 5 e 6 ilustram a vazão da água drenada e volume acumulado ao longo do tempo, que estão relacionados com a fase de drenagem. As Figuras $7 \mathrm{e}$ 8 mostram a porcentagem de redução de volume e a influência das variáveis climáticas para as primeiras 24 horas de ensaio.

Os valores de vazão da água drenada com o tempo e o volume acumulado de água de drenagem são apresentados, respectivamente, na Figura 3 e Figura 4. A partir da Figura 3, observou-se que a vazão de drenagem inicial para o $\mathrm{PACl}\left(\mathrm{Q}=20,0 \times 10^{-3} \mathrm{~L} / \mathrm{s}\right)$ foi mais eleva- da que para o sulfato de alumínio $\left(\mathrm{Q}=5,6 \times 10^{-3} \mathrm{~L} / \mathrm{s}\right)$, tendência apresentada até o final da drenagem. Pode-se inferir também, a partir das Figuras $3 \mathrm{e}$ 4 que a fase de drenagem é mais rápida e encerra em menor tempo para os lodos provenientes de $\mathrm{PACl}$.

A drenagem de água livre para o $\mathrm{PACl}$ encerrou aproximadamente após 1 hora, dando início às aberturas na massa do lodo e à secagem por evaporação. $\mathrm{O}$ volume acumulado coletado a partir da drenagem da água livre foi de aproximadamente $18 \mathrm{~L}$. Entretanto, para o lodo de sulfato de alumínio a drenagem de água livre prosseguiu por 6 horas, conforme pode ser observado na Figura 5, quando só então atingiu o volume acumulado de $18 \mathrm{~L}$.

A influência da precipitação na vazão de drenagem da água livre é mostrada na Figura 6.

Nota-se na Figura 6 que, após ocorrência de chuva (precipitação), houve aumento considerável na vazão de drenagem, ou seja, a água de chuva não se incorporou à massa de lodo, não ficou retida no leito e drenou rapidamente com vazão mais elevada que a inicial: para o $\mathrm{PACl}\left(\mathrm{Q}=42 \times 10^{-3} \mathrm{~L} / \mathrm{s}\right)$ e para o sulfato de alumínio $\left(\mathrm{Q}=38 \times 10^{-3} \mathrm{~L} / \mathrm{s}\right)$.

A Figura 7 ilustra o aspecto dos lodos de PACl e Sulfato de Alumínio, após uma hora de aplicação. Nota-se uma grande diferença nas quantidades de água, entre os dois lodos, em um curto período de tempo.

$\mathrm{Na}$ Figura 8 apresenta-se a variação dos valores de concentração de sólidos em porcentagem (\%) durante 24 horas, considerando a ocorrência de precipitação.

A ocorrência de chuva (precipitação) não interferiu na redução de umidade da massa de lodo, ou seja, no aumento esperado da porcentagem de sólidos, pois a água da chuva não se incorporou à massa de lodo, como pode ser observado no gráfico da Figura 8. 
Achon, C. L.; Barroso, M. M.; Cordeiro, J. S.

Tabela 3 - Variáveis operacionais monitoradas durante ensaios de desaguamento em leito de drenagem

\begin{tabular}{c}
\hline Variáveis operacionais \\
\hline - tempo de drenagem (desaguamento); \\
- tempo de secagem; \\
- variação da altura da massa de lodo aplicada no leito; \\
$\quad$ taxa de drenagem \\
(variação da vazão ao longo do tempo); \\
- porcentagem de sólidos totais.
\end{tabular}

Tabela 4 - Caracterização das amostras de lodo utilizadas nos ensaios de desaguamento em leito de drenagem

\begin{tabular}{cccc}
\hline Amostras de lodo & ST (\%) & \multicolumn{2}{c}{ Sólidos sedimentáveis $(\mathrm{mL} / \mathrm{L})$} \\
& & $1 \mathrm{~h}$ & $2 \mathrm{~h}$ \\
\hline Sulfato de alumínio & 2,6 & 550 & 470 \\
PACl & 1,4 & 470 & 450 \\
\hline
\end{tabular}

Ensaio de Coluna de Sedimentação

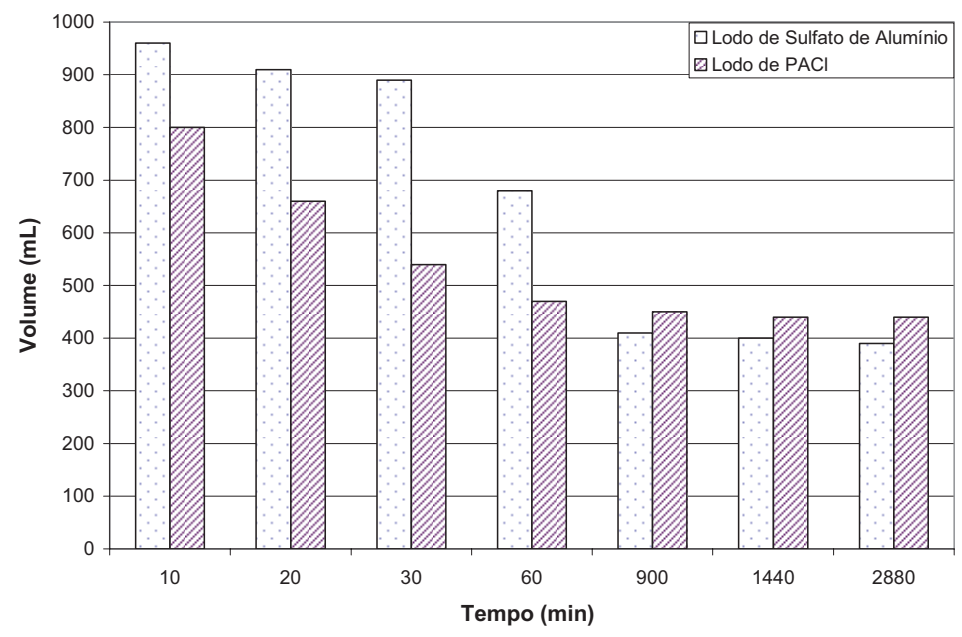

Figura 3 - Curva de sedimentação dos lodos de sulfato de alumínio e $\mathrm{PACl}$

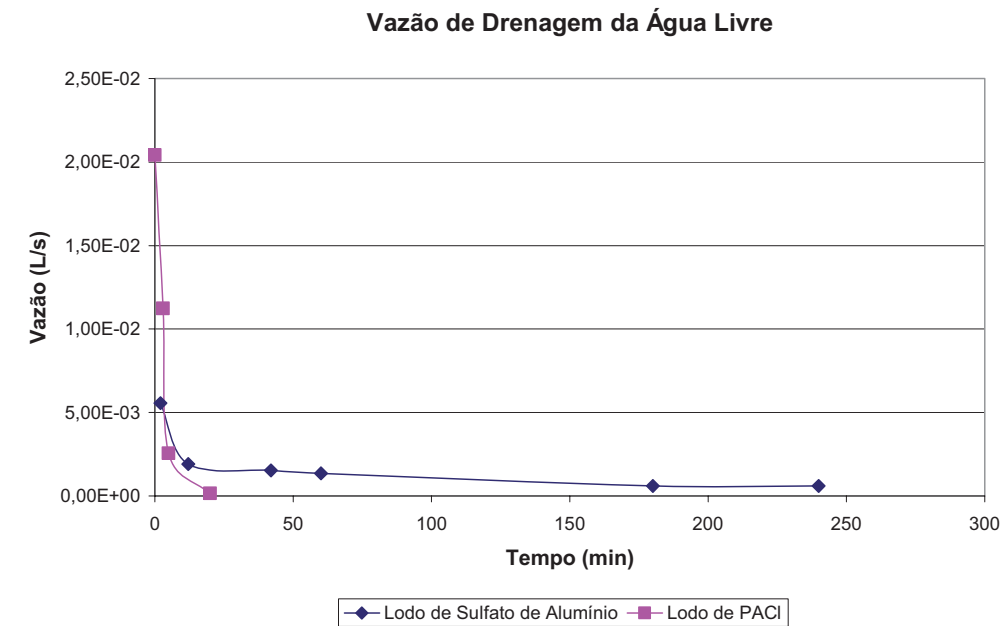

Figura 4 - Variação da vazão de drenagem da água livre (em L/s) para os lodos de sulfato de alumínio e PACI durante

as primeiras 5 horas 


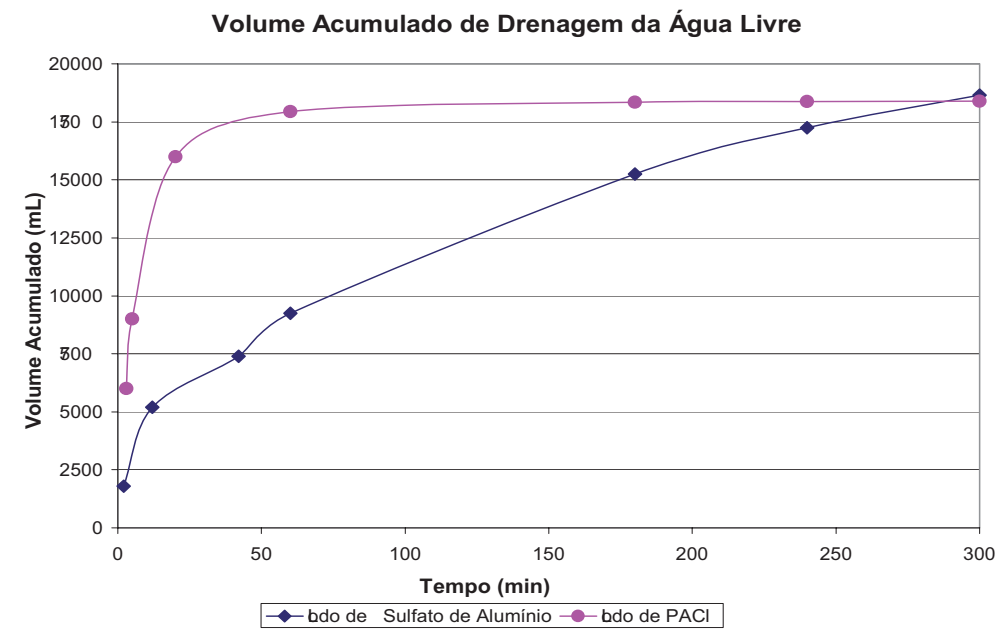

Figura 5 - Volume acumulado de drenagem da água livre para os lodos de sulfato de alumínio e PACI

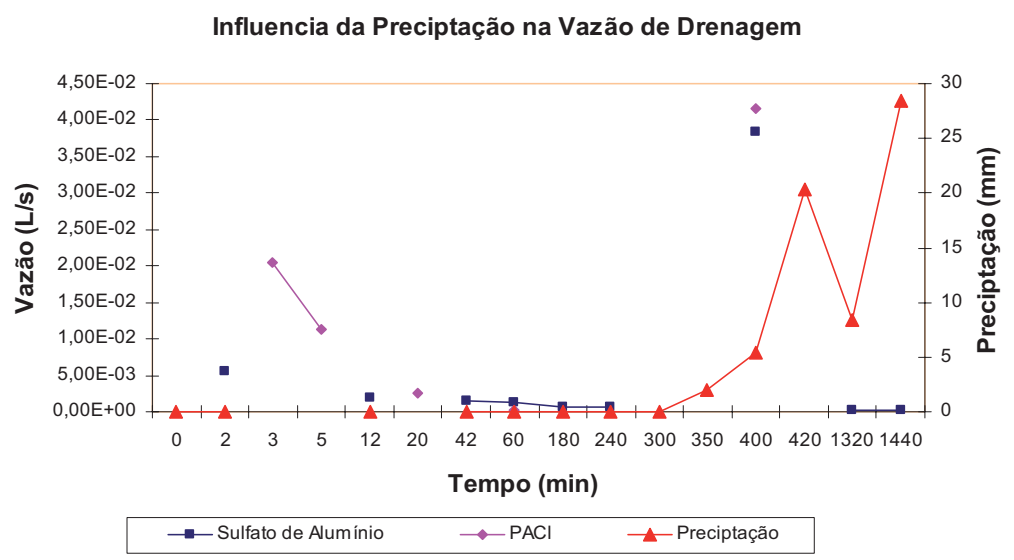

Figura 6 - Influência da Precipitação na vazão de drenagem da água livre (em L/s) para os lodos de sulfato de alumínio e PACl durante 24 horas

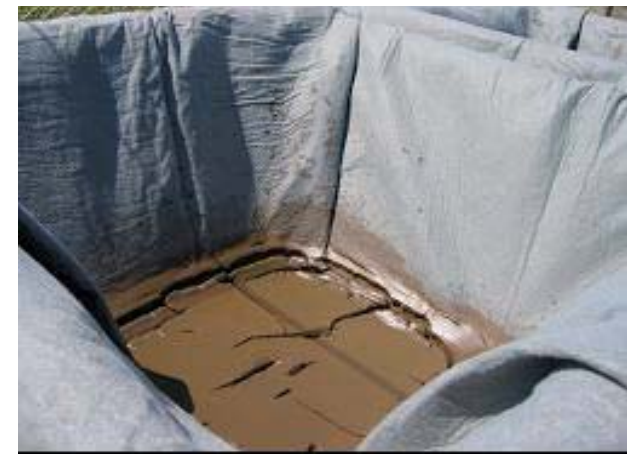

Lodo de PACI

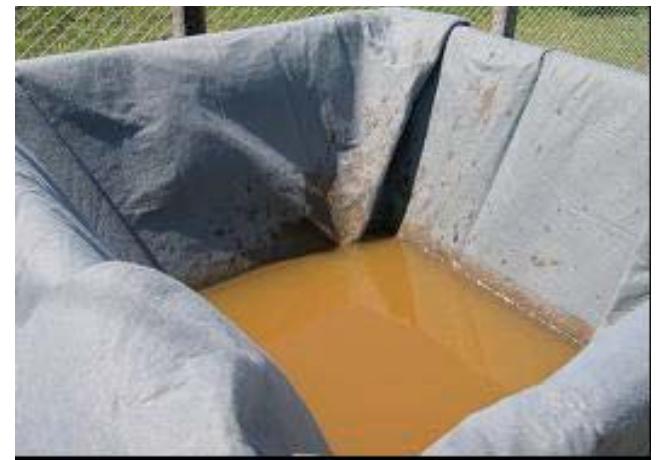

Lodo de Sulfato de alumínio

Figura 7 - Fotos dos Leitos de Drenagem após I hora de aplicação dos lodos de PACI e Sulfato de Alumínio 


\section{Secagem dos lodos nos leitos de drenagem}

Após o término da drenagem, iniciou-se a secagem do lodo, o qual foi monitorada diariamente. Nesta etapa de secagem foram medidas as alturas do lodo, em cada um dos leitos, e também foram coletadas amostras do lodo para determinação do teor de sólidos. $\mathrm{Na}$ Tabela 5 são apresentados a variação dos valores de concentração de sólidos dos lodos retidos no Leito de drenagem, que demonstram o desempenho e evolução durante a fase de secagem.

$\mathrm{Na}$ Figura 9, tem-se uma fotografia tirada depois de 24 horas da aplicação do lodo. A porcentagem de sólidos totais obtida após 24 horas foi de $9 \%$ para o $\mathrm{PACl}$ e $13 \%$ para o Sulfato de Alumínio.

A Figura 10 ilustra o aspecto dos lodos de PACl e Sulfato de Alumínio, após sete dias de aplicação. Nota-se considerável redução de volume, para ambos, quando comparados à fase inicial, Figura 7. Ressalta-se que a porcentagem de sólidos totais obtida em sete dias foi de $28 \%$ para o $\mathrm{PACl}$ e $31 \%$ para o Sulfato de Alumínio.

O lodo de PACl obteve uma redução de volume de aproximadamente $42 \%$ em 5 minutos, em 1 hora $78 \%$ e entre 3 e 6 horas estabilizou em $80 \%$. Já o volume de lodo de Sulfato de Alumínio reduziu apenas $28 \% \mathrm{em} 1$ hora, e após 6 horas $71 \%$. Estes resultados estão representados na Figura 11.

Com ocorrência de chuva após 6 horas de aplicação, houve uma queda momentânea de reduções de volume. Porém, após o término da chuva voltaram a se estabilizar e ambos os lodos voltaram a reduzir de volume. Ao fim de 7 dias houve redução de aproximadamente $87 \%$ e $83 \%$ do volume para os lodos de PACl e Sulfato de Alumínio respectivamente.

\section{Caracterização do drenado}

Os resultados da caracterização físico-química da água drenada em ambos os leitos, estão apresentados na Tabela 6 .

Os resultados apresentados na Tabela 6 demonstram o potencial para reutilização da água drenada. Nota-se que, apenas nos primeiros cinco minutos, esta água apresenta cor e turbidez elevada para ambos os tipos de lodo.

Assim, confirmou-se a tendência observada em outros ensaios realizados

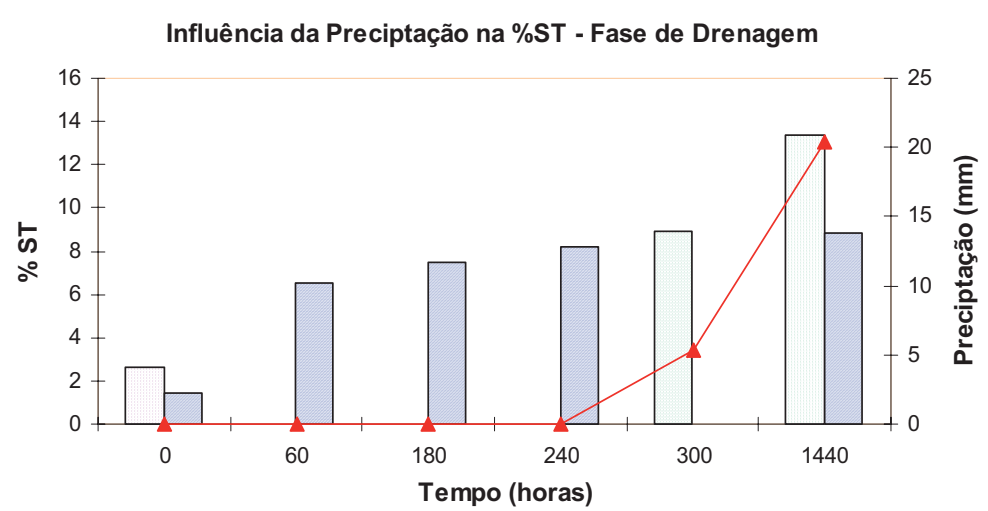

$$
\square \text { Sulfato de Alumínio } \amalg \mathrm{PACl} \longrightarrow \text {-Preciptação }
$$

Figura 8 - Influência da precipitação na variação da porcentagem de sólidos totais para os dois tipos de lodo durante $\mathbf{2 4}$ horas

Tabela 5 - Variação do valor de concentração de sólidos em ST (\%) nos lodos retidos nos Leitos de drenagens

\begin{tabular}{ccc}
\hline $\begin{array}{c}\text { Tempo } \\
(\text { dia })\end{array}$ & \multicolumn{2}{c}{ Valor de concentração de sólidos em ST (\%) } \\
Lodo de sulfato de alumínio & Lodo de PACl \\
\hline 0 & 2,6 & 1,4 \\
1 & 13,4 & 8,8 \\
2 & 15,5 & 11,1 \\
3 & 16,8 & 11,9 \\
4 & 23,3 & 22,7 \\
5 & 22,3 & 19,0 \\
6 & 23,6 & 20,6 \\
7 & 30,6 & 28,4 \\
21 & 79,9 & 88,0 \\
\hline
\end{tabular}

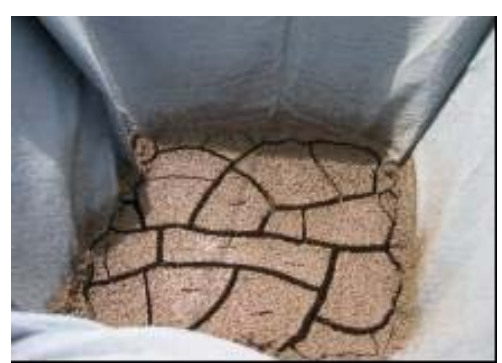

Lodo de PACl - ST= 9\%

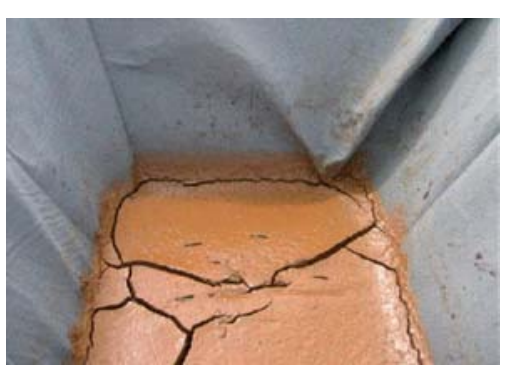

Lodo de Sulfato de alumínio - ST= $13 \%$
Figura 9 - Fotos dos leitos de drenagem após 24 horas de aplicação dos lodos de PACl e Sulfato de Alumínio 


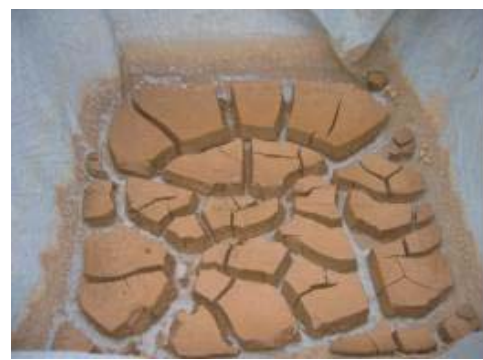

Lodo de PACl - ST= 28\%

Figura 10 - Fotos dos leitos de drenagem após 7 dias de aplicação dos lodos de PACl e Sulfato de Alumínio

Redução de volume de lodo em \%

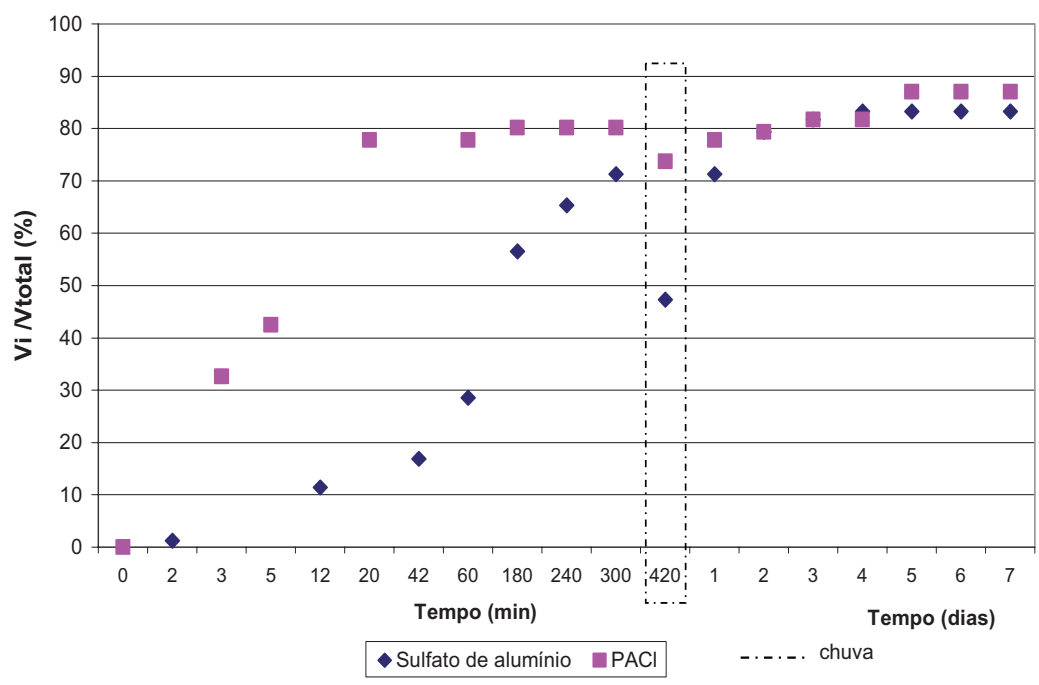

Figura I I - Variação da redução de volume de lodo em porcentagem

Tabela 6 - Características físico-químicas da água drenada nos dois protótipos

\begin{tabular}{ccccccc}
\hline $\begin{array}{c}\text { Tempo } \\
\text { (min) }\end{array}$ & \multicolumn{2}{c}{ Cor } & \multicolumn{2}{c}{ Turbidez } & \multicolumn{2}{c}{$\mathrm{pH}$} \\
& $\begin{array}{c}\text { Sulfato de } \\
\text { alumínio }\end{array}$ & PACL & $\begin{array}{c}\text { Sulfato de } \\
\text { alumínio }\end{array}$ & PACl & $\begin{array}{c}\text { Sulfato de } \\
\text { alumínio }\end{array}$ & PACl \\
\hline 0 & 984 & 118 & 135 & 29,3 & 6,4 & 6,6 \\
5 & 608 & 3 & 69 & 1,8 & 6,3 & 6,3 \\
60 & 57 & 4 & 4,8 & 1,1 & 7 & 6,8 \\
\hline
\end{tabular}

com esse protótipo, onde aproximadamente após 5 minutos apresentam-se baixos valores de cor e turbidez para água drenada (potencial de reutilização).

\section{CONCLUSÕES}

Os Leitos de Drenagem mostraram-se eficientes para o desaguamento e redução de volume de lodo de estaçóes de tratamento de água, que utilizam como coagulantes o Sulfato de Alumí-

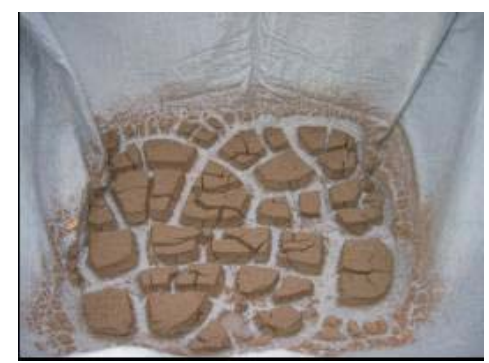

Lodo de Sulfato de alumínio - ST= 31\% de água livre para o lodo de PACl demorou uma hora, enquanto para o de Sulfato de Alumínio aproximadamente 6 horas.

Neste trabalho, a precipitação teve influência pontual ou momentânea, sem comprometer o desaguamento. Após ocorrência de chuva (precipitação), houve aumento considerável na vazão de drenagem, porém a água de chuva não se incorporou à massa de lodo, não ficou retida no leito e drenou rapidamente com vazão mais elevada que a inicial.

A água de drenagem proveniente dos lodos estudados, após cinco minutos de drenagem, apresentou baixos valores de cor e turbidez e conseqüente potencial de reutilização. Ressalta-se a necessidade de se estudar outros parâmetros que poderiam influenciar nos possíveis usos desta água.

Obteve-se, aos sete dias, reduções da ordem de $87 \%$ e $83 \%$ em volume para os lodos de PACl e Sulfato de Alumínio respectivamente. A porcentagem de sólidos totais ao final de sete dias foi de aproximadamente $28 \%$ para o lodo de PACl e 31\% para o Sulfato de Alumínio.

Conforme citado na metodologia e verificado por Fontana (2004), nos leitos de drenagem a manta pode ser reutilizada várias vezes após limpeza superficial.

As tecnologias, operações e processos das ETA podem influenciar nas características do lodo gerado. Assim, recomenda-se que mais pesquisas sejam feitos, para avaliar as micro e macro propriedades destes lodos e sua influência no desaguamento natural em Leitos de Drenagem.

Vale ressaltar que, as características dos leitos de drenagem desenvolvido por Cordeiro (2001) atenua a colmatação e facilita sobremaneira a drenagem, ao contrário do que observa-se em outros sistemas naturais de redução de volume de lodo de coagulantes foi praticamente a mesma. Porém notou-se que o PACl possui uma resposta mais rápida, ou seja, a vazão de drenagem inicial para o PACL é aproximadamente três vezes maior que a do Sulfato de Alumínio. A drenagem ETA, como por exemplo os leitos de secagem tradicionais e as lagoas de lodo.

\section{REFERÊNCIAS} dias, o teor de sólidos e porcentagem de redução de volume, para ambos os

nio e Cloreto de Polialumínio (PACl) de ou adição de produtos químicos.

A partir da análise conjunta dos Critica da Implantação de Sistemas Naturais de Remoção de volume de lodo de ETA. In: XXIX CONGRESSO INTERAMERICANO DE ENGENHARIA SANITÁRIA E AMBIENTAL (AIDIS), Anais. San Juan-Porto Rico, CD, I-Achon-Brasil-1. 2004.
ACHON, C.L.; CORDEIRO, J.S. Análise 
APHA - AMERICAN PUBLIC HEALTH ASSOCIATION. Standard Methods for The Examination of Water and Wastewater. 20.ed. Washington DC, USA. 2001.

ASSOCIAÇÃO BRASILERIA DE NORMAS TÉCNICAS. NBR-10.004. Resíduos Sólidos Classificação. Rio de Janeiro, ABNT. 2004.

BRASIL Leis (1998). Lei 9.605. Lei da Vida - A lei dos Crimes Ambientais. Brasília, DF. 1998.

BRASIL Leis. Lei 9.433 de 8 de Janeiro de 1997. Politica Nacional dos Recursos Hídricos. Brasília, DF. 1997.

CORDEIRO, J.S. O problema dos lodos gerados em decantadores de estaçôes de tratamento de águas. Tese (Doutorado) - Escola de Engenharia de São Carlos, Universidade de São Paulo. São Carlos. 342p. 1993.

CORDEIRO, J.S. Remoção Natural de Agua de Lodos de ETAs Utilizando Leitos de Secagem e Lagoas de Lodo. In: REALI, M.A.P (Coordenador). Nocōes gerais de tratamento e disposição final de lodos de estaçōes de tratamento de água. Projeto PROSAB, Rio de Janeiro: ABES, 250p. 1999.

CORDEIRO, J.S. Processamento de lodos de Estaçóes de Tratamento de Agrua (ETAs). In.: ANDREOLI, C.V. (Coordenador). Resíduos sólidos do saneamento: Processamento, reciclagem e disposição final. Rio de Janeiro: ABES. Projeto PROSAB 2. 282p. 2001.

CORNWELL, D.A. et al. Handbook water treatment plant waste management. AWWA, Research Foundation, Denver, 431 p. 1987.
FONTANA, A.O. Sistema de Leito de Drenagem e Sedimentador Como Solução Para Redução de Volume de Lodo de Decantadores e Reuso de Agua de Lavagem de Filtros - Estudo de Caso-ETA Cardoso. Dissertação (Mestrado) - Universidade Federal de São Carlos/UFSCAR. São Carlos. 2004.

FREITAS, R. A. S. Comportamento de geotêxteis como filtro em resíduos - Fosfogesso e Lama vermelha. Dissertação (Mestrado). COPPE/Universidade Federal do Rio de Janeiro. 122p, Rio de Janeiro, 2003.

HUBBS, S.A.; PAVONI, J.L. Opimization of sludge dewater ability in sludge - disposal lagoa. JAWWA, Denver, v. 66, n. 11, p. 658-663, nov. 1974.

REALI, M.A.P. Principais caracteristicas quantitativas e qualitativas do lodo de ETAs. In: REALI, M.A.P (Coord.). Noçôes gerais de tratamento $e$ disposição final de lodos de estaçóes de tratamento de água. Projeto PROSAB, Rio de Janeiro: ABES, p.250, 1999.

SMOLLEN, M.; KAFAAR, A. Electroosmotically enhanced sludge dewatering: Pilot-Plant Study. Water Science Technology. v. 30, n.8, pp. 159-168, 1994.

VESILIND, P.A.; HSU, C.C. Limits of sludge dewaterability. Water Science Technology. v. 36, n.11, pp. 87-91, 1997.
Endereço para correspondência:

Cali Laguna Achon

Rua Augusta Cantarim Zezza, 7 /4

Bairro Jardim Itaquerê

I3520-000 São Pedro - SP - Brasil

Tel: (I 9) 348 I-3099

Fax: (I9) 348I-493 I

E-mail:cali@sc.usp.br 